\title{
Development model of communicative ULA in primary school children with learning difficulties
}

\author{
Marina Skuratovskaya* and Elena Romanova \\ Don State Technical University, 344003, Rostov-on-Don, Russia
}

\begin{abstract}
The article presents the model of the formation of communicative (universal learning actions) ULA, which includes the principles and stages of remedial and pedagogical activities of speech and socio-psychological development. Each stage is supposed to work on communicative ULA development in primary school students with learning difficulties. There are three main directions of the communicative ULA development: the development of cognitive processes, the development of speech skills, and the development of socio-psychological skills. This article also presents the content of remedial and pedagogical work, including various types of activities in the curricular and extracurricular types of organizing educational activities.
\end{abstract}

\section{Introduction}

The communicative universal learning actions (ULA) - is the important group of universal learning activities, which involves the ability to interact, active participation in a dialogue and collective discussion and to cooperate with adults and peers [1].

The problem of communicative development is particularly relevant in relation to students with learning disabilities, who make up the main contingent of students with learning difficulties.

The main contingent of primary school children with learning difficulties in comprehensive schools are children with learning disabilities, who study according to the adapted general education program $[2,3,4,5,6]$. These learning difficulties are associated with "specific features of speech development, a reduced level of working ability and stability of attention, as well as a reduced level of cognitive activity" [7,8]. All these specific development features of primary school children lead to the difficulty of forming communicative universal learning actions (ULA).

Our previous study [7] revealed the specificity of each of the three communicative ULA components: communication as cooperation, communication as interaction, and communication as a condition of interiorization. In each of these types of communication skills, we divided them into two groups: speech and socio-psychological communication skills. [9]

\footnotetext{
* Corresponding author: marinasku@yandex.ru
} 
The results of the diagnostics showed that the lowest indicators in primary schoolchildren with learning difficulties were noted in the study of communication as interaction, which may be causedby the need for the development of speech skills and socio-psychological skills. The study of communication as cooperation showed such difficulties as the inability to ask questionsmake a dialogue and make clear expressions, exchange the necessary information, as well as the inability asking for help when planning teamwork. The third type of communication skills - communication as interiorisation - was characterized by the difficulties withmaking instructions and questions, as well as the ability tonegotiatesplitting the tasksduring a teamwork." [9].

The quantitative characteristics of the results of the study are shown in the Table 1

Table 1. The development level of communication skills in children with learning difficulties

\begin{tabular}{|l|c|c|c|c|c|c|}
\hline \multirow{2}{*}{ level } & \multicolumn{2}{|c|}{$\begin{array}{c}\text { Communication as } \\
\text { interaction }\end{array}$} & \multicolumn{2}{c|}{$\begin{array}{c}\text { Communication as } \\
\text { cooperation }\end{array}$} & $\begin{array}{c}\text { Communication as } \\
\text { a condition of } \\
\text { interiorization }\end{array}$ \\
\cline { 2 - 7 } & $\begin{array}{c}\text { Speech } \\
\text { skills }\end{array}$ & $\begin{array}{c}\text { Socio- } \\
\text { psychological } \\
\text { skills }\end{array}$ & $\begin{array}{c}\text { Speech } \\
\text { skills }\end{array}$ & $\begin{array}{c}\text { Socio- } \\
\text { psycho- } \\
\text { logical } \\
\text { skills }\end{array}$ & $\begin{array}{c}\text { Speech } \\
\text { skills }\end{array}$ & $\begin{array}{c}\text { Socio- } \\
\text { psycho- } \\
\text { logical } \\
\text { skills }\end{array}$ \\
\hline Low level & 76 & 100 & 83 & 93 & 90 & 80 \\
\hline Average level & 24 & - & 27 & 7 & 10 & 20 \\
\hline High level & - & - & - & - & - & - \\
\hline
\end{tabular}

\section{Research Materials and Methods}

The results of the study allowed us to createthe development model of communicative ULA in primary school children with learning difficulties.

The main principles of remedial and pedagogical activity for the development of speech and socio-psychological skills in the structure of the communicative ULA inprimary schoolchildren with learning disabilitiesare:

1. Step-by-step. This principle involves the stages of communicative ULA development in accordance with the forms of communication, which represent qualitative changes in the child's communicative activity in the process of ontogenetic development.

2. Relationship between speech development and mental functions, which reveals the relationship between the level of speech development and mental functions that form the basis for the of communicative ULA development. This fact aims to work on the development of speech and mental functions at the same time in students with learning difficulties.

3. Systematicremedial and developmental work thatincludes development of communication as interiorization, communication as interaction, communication as cooperation. The content of remedial and pedagogical activities should include speech development work and socio-psychological development work in each structural component. At the same time, the step-by-steptasks involves a consistent change of the priority task at each of the stages.

4. Differentiated and personal approach, which focuses on taking into account the difference between levels of speech and psychophysical development inpupils with learning disabilities and normal development students.

5. Special educational settings that assumes a communicative orientation in the curricular and extracurricular activities. This principle involves the coordinated activity of 
teachers, psychologists, speech therapists and parents of children with learning difficultiesfor developing pupils' communicative skills.

According to the step-by-stepprinciple, we identified three stages of the communicative ULA development.

The first direction assumes the development of mental functions, which form the psychological basis of pupils` speech. The theoretical analysis of the research showed that students with learning disabilities have perception, attention, speech and memorydelay [10, $11,12,13,14,15]$.These functions provide the background for successful development of communicative activity.

The second direction of remedial and pedagogical work of communicative ULA development is the speech skills development that provides the vocabularyusage, the correctexpression constructions and grammatical forms usage.

The third direction assumes socio-psychological development in primary school children with learning difficulties, which provides the child's ability to interact with peers in various types of activities, an emotionally positive approachin ateamwork, the ability to negotiate, understand different positions and points of view,help and ask for help.

At the first stage, the leading direction is the development of mental functions. The tasks were solved: the development of fine motor skills, the development of educational motivation; the sensory development; the mental processes development- concentration, stability and switching of attention, conscious perception, abstract-logical and imaginative thinking.

At the first stage the maim form of interaction was the child - teacher system. The teacher had a leading role, directing the child's communicative activity in the correct direction, giving them a sample.

We were developing the mental functions during thecurricular and extracurricular activities. We are developingfine motor skillsduringTechnology lessons and Art lessonsusingpainting non-traditional technologies, modeling and finger game training. Sensory development included using games and exercises for the visual development, auditory and kinesthetic perception: exercises for grouping objects by size, material, and shape, comparing objects by height, color difference, the ability to combine colors; games for the spatial arrangement of objects; exercises on the differentiation ofspeech and nonspeech sounds. The developingmental processes work involved usingthe games and exercises for concentration, stability and switching of attention.

The speech developmentwork at the first stage assumed developmentof ability to ask questions. We were developingspeech skillsduring the curricular activity. For example, in Maths classes we used the "teacher's sample" technique, when the children solved the problem by asking questions («Which question should be answered in the problem? What do we need to know to answer the question? How do I find an unknown number? How can I check that the problem was solved correctly?»).

The socio-psychological development at this stage involved the development of children's emotionally positive attitude to teamwork; the ability to ask forhelp the ability to understand different positions and points of view. These tasks were solved during the psychological classes and involved the communicative games that promote the development of a positive attitude to the peers.

At the second stage, the leading direction was the development of speech skills and speech activity of primary school children with learning disabilitiesaccording to the vocabulary developed during the first stage. We were solving the tasks of developing conversational speech, the ability to obtain the necessary information by means of questions; to make understandable expressions.

The main form of interaction at the second stage was the child-peer system. This system involves the organization of students' activities with an adult's help so that the students' 
teamworkcould be aimed at achieving a certain result. (the teacher chose the partner for the pupils`activity).

The following types of activities represent remedial and pedagogical work at this stage: working with books, working with learning handouts, listening and analyzing the speeches of the interlocutors, checking and discussion of written works, game activities. Such activities as working with books, working with learning handouts, reviewing and discussing written works, listening and analyzing the speeches of the interlocutors, we included in the curricular activities of all subjects. Game activities are presented in the form of communicative games, which we included both in the curricular activities and in psychological classes.

We began to develop speech skills inLiterature classes and used the chain reading technique androle-playing reading. In Russian classes, we worked on the text content and asked students to fill out the table with questions after reading a small text. Each pair of students gotthe learning handout: the paper with questions "Who? What? When?" and answer options on the paper. One of the students asked a question, for example, "Who is the hero of the story?"," What did the hero lose? " The other student chose the correct answer, put his answer in the appropriate column of the table, then he (she)gave the answer in a full sentence.

After the children learned how to make understandable questions to the interlocutor,we consolidated this skill in Art class, asking each other questions about the closed picture "Painting a landscape with watercolors". During the lesson, the children were divided into pairs. A couple of pupils were sitting with their backs to each other, oneof themhad a paper and watercolors, the other had a finished picture. A student with a paper had to do the same job as the other person, asking questions.

During the development of socio-psychological skills, the following tasks were solved: to develop the ability to be active in solving various tasks during interaction; to ask for help, as well as to offer help and cooperation. The main task in the developmentof the ability to be active in solving various tasks was to increase the interest of students during the curricular activity. We found the most favorable conditions for increasing the motivation of students with learning disabilities during the organization of non-standard lessons, for example, a excursions to the a park, a fairy tale-lessons in Mathsclasses, a journey-lesson in Literature classes. The development of the asking for helpskills as well as to offer help and cooperation, we carried out during extracurricular activities, which involved politeness lessons, conversations about cooperation, manners classes and communication games.

The development of mental functions at this stage involved the following tasks: the development of logical operations-analysis, synthesis, comparison, generalization, classification, judgment, inference. We included learning games and exercises for the development of mental operations, the topic of which was selected according to the curriculum.

At the third stage, the remedial and pedagogical work associated with the development of socio-psychological skills, which included the development of the ability to find a common solution; to formulate one's own opinion and position; to agree on the distribution of functions and roles in the teamwork.

The main form of interaction was the child - peer system. The difference is connected with the organization of independent teamwork of primary school students with learning difficulties in a group.

The following types of activities represent developmental and pedagogical work at this stage: observation, experiment, research activities, work with books, solving problems with explanation, we carried out during the curricular activity. Competitions, playing around real 
situations, solving entertaining tasks, designing bannerswere organized as a part of extracurricular activities.

The ability find a common solution was developed in the course of curricular and extracurricular activities. The situations were created during theteamwork, when students changed roles in the group and performed different functions throughout the lesson. For example, we had a survey in Russian and Maths classes in a group of 3-4 students. The pupils distributed the roles among themselves. Someone played the role of the examiner, another student told the rule or explained the writing, the third student supported the answer with examples, and the fourth student evaluated the responses of the interlocutors.

We alsodeveloped the ability to make own opinion and position in the course of curricular and extracurricular activities. We organized a homework checking in pairs in Russian and Mathsclasses. We gave instructions to ask each other questions about the completed task of the interlocutor, compare the version of their completed homework and the task of the interlocutor, note mistakes and evaluate their work and the peer's work.

The development of speech skills at the third stage is aimed at developing the ability to speak the essential directions of action that are understandable to the partner; to conduct oral and written conversation in accordance with the grammatical and syntactic norms of Russian language; the monologue development. We solved these problems in the course of our curricular activity using the technique of retelling texts according to the plan.

Before developing the children's ability to make a monologue, we taught students to ask questions such as "What is the difference..?", "Explain why..?", "Why do you think so?". Children got the cards with questions and a task to finish the questions after reading a small text. One of them completed and asked questions, the other student answered, and then the students change roles. We also proposed a task: to make a simple sentence according to the scheme. This work was organizedas a pair work - one of the students offered a sentence scheme, the other one made a sentenceaccording to the scheme.

During the development of mental functions as the basis for the development of speech and social-psychological skills in the structure of communicative ULA, we gave the tasks of developing verbal-logical thinking. These tasks were solved during extracurricular activities which were focused on the development of verbal and logical thinking through research, solving entertaining problems, learning exercises, such as "Find a logical connection between objects", "Prove that one subject is different", "The distribution of words according to the logical principle".

\section{Conclusion}

Summing up the results of the development model of communicative ULA in primary school children with learning difficulties, we have done the following conclusions.

The model developed by us for the development of communicative ULA in primary school children with learning difficulties includes three related stages of remedial and pedagogical work. At each stage of the communicative ULA development, the work was carried out within the three main components: communication as interiorization, communication as cooperation, communication as interaction. Each of them included the development of mental functions, speech skills and socio-psychological communication skills.

At each of the three stages of the communicative ULA development, one of the areas of remedial and pedagogical work was the leading one, although work on the other two areas was also carried out. From stage to stage, the focus of pedagogical attention moved from one direction to another in accordance with the principle of consistency and the principle of interaction between the development of speech and mental functions. 


\section{References}

1. M.E. Gifford-Smith, C.A. Brownell, Journal of School Psychology 41 (4), 235-284 (2003).

2. G. Laws, G. Bates, M. Feuerstein, E. Mason-Apps, C. White, Child Language: Teaching and Therapy 28 (1), 73-86 (2012).

3. S.M. Redmond, Language, Speech, and Hearing Services in Schools 42 (4), 520-535 (2011).

4. R.D. Triger, Psychological features of socialization of children with learning disabilities (Piter, St. Petersburg, 2008).

5. B. Menting, P.A.C., van Lier, H.M. Koot, Journal of Child Psychology and Psychiatry 52 (1), $72-79$ (2011).

6. Natalia Berdnikova, Natalia Abashina, E3S Web of Conferences 210, 18001 (2020).

7. R.A. Dunilova, Management of elementary school 5, 15-22 (2013).

8. M.L. Skuratovskaya, E.A. Romanova, The World of Academia: culture and education 10 (2020). (UDC 376.42 DOI 10.18522/2658-6983-2020-10-123-132)

9. Olga Fedotova, Vladimir Latun, E3S Web of Conferences 210, 18065 (2020). DOI https://doi.org/10.1051/e3sconf/202021018065.

10. M. Skuratovskaya, E. Romanova, E3S Web of Conferences 210, 18096 (2020). DOI https: //doi.org/10.1051/e3sconf/202021018096.

11. D.F. Hay, A. Payne, A. Chadwick, Journal of Child Psychology and Psychiatry 45 (1), 84-108 (2004).

12. S. Graham, K.R. Harris, Common Core State Standards, writing, and students with LD. Learning Disabilities Research \& Practice (2013) 28-37.

13. L.I. Lazareva, Elementary school 6, 76-78 (2014).

14. L.M. Troesch, K. Keller, A. Grob, European Psychologist 21 (3), 167-179 (2016).

15. F. Van der Wilt, C. van Kruistum, C. van der Veen, B. van Oers, An explorative study in early childhood education. European Early Childhood Education Research Journal 24 (6), 807-817 (2016). 